\title{
J
}

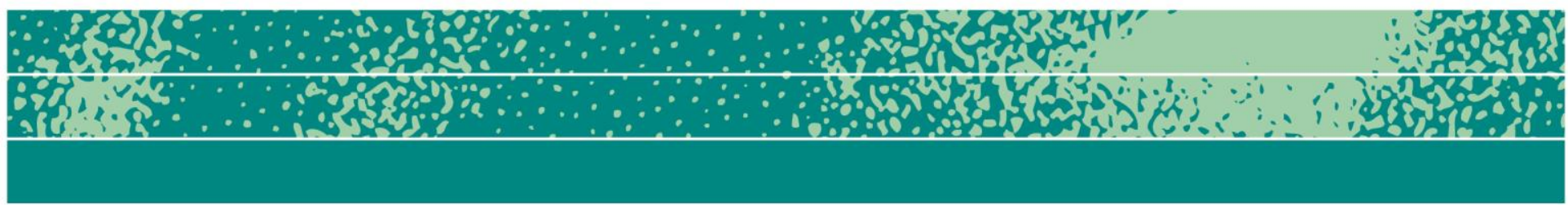

\section{Possessed by the Zeitgeist: Inspiration and Prophecy in the Business of Fashion}

\author{
Kasper Tang Vangkilde
}

\begin{abstract}
The ability to foretell the future-and, as such, to conquer and determine it-is an essential preoccupation of contemporary business, which supposedly distinguishes the winners from the losers. The business of fashion is perhaps the case in point, being inherently concerned with continually staking out new paths into the future. In this article, I explore how fashion designers deal with this imperative through processes of seeking inspiration, constituting a distinctive "technology of prefiguration" by which the designers come to enter a prophetic condition. Rooted in an animistic mode of being, this attests to a shamanic practice, which entails the designers becoming possessed by a zeitgeist and, hence, turning into prophetic agents with particular visions of the future. The world of fashion is, in this sense, populated by entities and processes not commonly associated with modern business, in that animistic tendencies, jumping things, spiritual beings and shamanic efforts enable the designers to attain otherwise unattainable prophetic viewpoints. Underlying this argument is a more general ambition to open up our conception of business, as I suggest that business anthropologists may do well to uphold a profound naïveté in their methodology, which may essentially challenge and revise our assessment of modern capitalism.
\end{abstract} Page 1 of 23

JBA 4(2): 178-200 Fall 2015

(C) The Author(s) 2015 ISSN 2245-4217

www.cbs.dk/jba 


\section{Keywords}

The future, inspiration, prophecy, prefiguration, animism, shamanism, fashion

"You always have to be in the zeitgeist. You know?" Catherine pauses and looks at me, as if she wants to make sure that I am not completely lost. "Yeah, in the time spirit," I respond briefly, trying not to interrupt her flow of speech. We are engaged in a conversation about fashion and, in particular, what it is that makes a good fashion designer. And Catherine, a fashion designer by training, has quite a few things on her mind. "So, you have to have this feeling for this time spirit in a way, because then you know basically what people are going to like in maybe one year." Now, I probably look more puzzled, thinking hard about what she is actually saying. Catherine senses my puzzlement immediately. She elaborates:

If you know a lot about what is happening in the world, you can also already imagine how things might be in one or two years' time. There are a lot of trend reports and things like this, but it's not only this. You have to kind of feel it or take it in.

Indeed, the ability or endeavour to anticipate the future and, in the same process, to bend it in a particular direction is an essential preoccupation of modern western business. This is nothing new, of course. About 20 years ago, business gurus Gary Hamel and C. K. Prahalad emphasized in their bestseller Competing for the Future (1996), a book notoriously "not about catching up" but "about getting ahead" (ibid. $x$ ), that "[e]very company is in the process of becoming-of becoming an anachronism irrelevant to the future, or of becoming the harbinger of the future" (ibid. xi). For this reason, a number of sustained efforts to prefigure the future so as to "colonize" it strategically prevail in business organizations: big data analytics, user-driven innovation, design thinking workshops, prototyping, coolhunting and trendspotting are just a few examples of diverse kinds of "technologies of prefiguration" (see Jiménez 2013), which seek to explore and capture, here and now, what is yet to come. The future, in a nutshell, is both a potentially valuable and highly contested space.

As we all know, a defining characteristic of the future is precisely that it is so hard to foretell and, thus, inherently uncertain. The business of fashion is no exception. In fact, as the economist Richard Caves argues, creative industries are essentially characterized by a "nobody knows property," which denotes the fact that no one can know with certainty how consumers will respond to new products. Demand is, as such, highly uncertain and success unpredictable (2000:2-3; see also Moeran 2005:172-173). In this respect, Catherine, as well as other fashion designers, clearly believe that trend reports, market research and the like 
will only take you so far (see also Entwistle 2009:138). Instead, "you have to know the time spirit," as Rebecca, another fashion designer, contends. "You have to have a feeling for the time, or era in which we're living." Her reason seems clear enough:

"Some people are doing foresight research to tell what is going to happen, and I think that a good designer should have just a feeling, so that when he sees something he knows that maybe it could become important. Just a feeling about the time and what is going to happen."

Referring to a zeitgeist is certainly not uncommon among fashion designers, and the notion has been much debated in fashion research as an explanation of fashion changes. In the most cited but also most clichéd interpretation, it has been suggested, for instance, that hemlines tend to drop during economic depressions and rise during economic booms (cf. Entwistle 2000:63-64). Apart from such a problematic, simplistic and reductionist theory, Herbert Blumer famously argued that fashion is a result of a process of collective selection in which designers, buyers and other agents make significant choices about which designs to create, buy and promote. Although highly competitive and secretive, these agents make surprisingly similar choices, which, according to Blumer, are due to their immersion in, and responsiveness to, "a remarkably common world of intense stimulation" (1969:279); that is, "a 'spirit of the times' or a zeitgeist" (ibid. 283). The key point remains, however, that the zeitgeist is exclusively discussed as an analytical concept rather than as an empirical reality which is considered serious business by a range of agents-not least by Catherine, Rebecca and other fashion designers. Should we not then, as anthropologists, take descriptions of it just as seriously as anything else?

In this article, I intend to do this by focusing attention on fashion designers' persistent concern with becoming inspired. Drawing on ethnographic fieldwork in HUGO BOSS, a leading European fashion company, ${ }^{1}$ I shall argue the following: processes of inspiration constitute a distinctive technology of prefiguration by which fashion designers enter a prophetic condition. Or, to put it differently, the sustained endeavour to become inspired is a particular way of dealing with the imperative of modern capitalist business to anticipate an inherently uncertain future. This entails two main processes. First, inspiration serves to impose a spatial distance on existing things and phenomena, allowing designers to envisage a fashion collection from a new perspective. Second, inspiration serves to impose a temporal distance on the present, enabling designers

\footnotetext{
${ }^{1}$ The fieldwork was conducted over eight months in 2007. Puzzled by the fact that fashion designers face the challenge of being creative in highly specific time interval-for instance, in season-I gained access to HUGO BOSS for the purpose of exploring how creativity, itself a "fashionable" phenomenon in the late modern world, unfolds in practice.
} 
to see-or see from-a future point in time. Recalling the etymology of the term "in-spiration," meaning the blowing of spirit into a subject or the possession of a subject by a superior power (cf. Salamon 2005:48), I contend that these processes are deeply rooted in an animistic condition of being-that is, a tendency to perceive nonhuman entities as being alive-which forms the basis for a shamanic practice by which the designers become possessed by the zeitgeist-and, as such, turn into prophetic agents with particular visions of the future. ${ }^{2}$

Now, if this sounds somewhat radical, it is indeed my point. Following certain recent trends in anthropology, I subscribe to the view that we ought to be careful not to substitute surprising things and phenomena encountered in fieldwork with recourse to more familiar conceptions, thus explaining our surprises away (see e.g. Henare et al. 2007a; Latour 2005). While it is surely possible to analyse and, in a sense, deconstruct the zeitgeist as an obvious articulation of the romantic trope of "the creative person," representing a sort of emissary of the divine (Negus \& Pickering 2004:3-4), such an analysis would fail to take seriously what the designers themselves take seriously, relegating their experiences, perceptions and beliefs to mere romanticism; that is, they may think and say this, but $I$, as an anthropologist, know better (see also Willerslev 2007:181-182). As the key objective of anthropology is, I believe, "to open up the world, rather than to seek closure" (Ingold 2008:84, original emphasis)-that is, to continually explore "new possibilities for thinking about experience" (Jackson 2013:88)-it is imperative that we uphold a profound naïveté and refrain from limiting in advance our understandings and conceptions. ${ }^{3}$ Indeed, this may be particularly crucial in business anthropology, which tends to focus on contexts and activities that are "deceptively familiar" (Krause-Jensen 2013:43). In what follows, this methodological strategy shall lead us to see a world of business awash with entities and processes-animistic tendencies, jumping things, spiritual beings, shamanic practices, prophetic agents-which deeply challenge and revise our common assessment of what modern capitalist practices entail; and, as such, of what it, more generally, means to be modern. Even hard-core business may be in-spired.

\footnotetext{
2 While a few studies have argued that "sources of inspiration are essential for continuing creativity" (Eckert \& Stacey 1998; see also Mete 2006), the processes of inspiration remain largely a black box in research on fashion.

${ }^{3}$ As Bruno Latour emphasizes: "We have to resist the idea that there exists somewhere a dictionary where all the variegated words of the actors can be translated into the few words of the social vocabulary. Will we have the courage not to substitute an unknown expression for a well-known one?" (2005:48, original emphasis).
} 


\section{Capacitating spaces-and relating to the world as continuous birth}

For fashion designers, just about anything can be a source of inspiration. Or so, at least, it appears. We know, for instance, that Giorgio Armani was once inspired by the mountains of Mongolia and China (Davis 1992:128), John Galliano by different images from the time of Napoleon (Mete 2006:284) and Elsa Schiaparelli by Salvador Dalís Lobster Telephone (ibid. 286). One could, therefore, easily be fooled into believing that the particular place to become inspired is not important. This is, however, far from the case. In fact, discussions about where to go on so-called "inspiration trips" can be fairly intense, as fashion designers tend to find it critical to be in the right place to become inspired-and the right place often differs not only from season to season but also from designer to designer. For the Creative Director of BOSS Orange, a more casual brand in HUGO BOSS, places with second-hand stores and street markets are particularly inspiring:

"I don't go to the chic places to see people who are dressed in Gucci, Prada or whatever. This doesn't give me anything really. Okay, people are well-dressed, but the new is not there. The new is always in the second-hand places."

I shall return to this rather intriguing and somewhat paradoxical statement about the new being in the second-hand places. For now, it should merely be noted that even if anything can potentially be inspiring, some places are believed to be significantly more inspiring than others. Such places, I suggest, can be seen as a kind of "clusters of inspiration" in that they are perceived to constitute particularly dense agglomerations of sources of inspiration. The point is that when the designers are probing into such clusters of inspiration, these places come to function as capacitating spaces, to rephrase a pair of terms put together by Alberto Corzín Jiménez (2003); that is, they come to capacitate or enable the designers to do things that would hardly be possible otherwise. Or, to be more precise, they come to function in this way if the designers are open to it. In the following, I shall give this point ethnographic substance by turning to a group of five talented fashion designers, employed for half a year at HUGO BOSS to work on a specific innovation project. ${ }^{4}$

Early on a Wednesday morning in February, I meet up with the fashion designers. In a presentation for the Creative Director a couple of days ago, the designers have received the discouraging message that their work is by no means progressing as expected. In fact, they are completely off track, having more or less misunderstood their task. Left with no clear

\footnotetext{
${ }^{4}$ I have described this project in much detail elsewhere, although for a different purpose (see Vangkilde 2013). Here, I therefore limit the description to a brief snapshot of one the inspiration trips in order to delve more deeply into inspiration in particular.
} 
idea on how to proceed with the project, the designers now find that they need to get away from the office in order to seek new inspiration. And since Milan, one of the world's most famous fashion cities, is nearby, we decide to spend the day here, visiting museums, bookstores, furniture shops, fashion stores, restaurants and bars. As such, we are all in a good mood, highly excited about what the day might bring.

Having visited the first museum, we discover a bookstore, as well as a store offering clothing, arts and crafts, right next to the museum. When we enter the stores, the designers walk around more or less separately, looking carefully at all the different things. Not all of these are, of course, equally exciting, as some of them are almost ignored while others are seen as much more fascinating. Among the latter are not merely shoes, bags, clothes and other fashion accessories but, just as often, or perhaps even more so, things of a quite different nature. Katja, for instance, is very interested in a book which she finds really cool. She shows me a few pages of it, in which pictures of CD covers from hard rock and heavy metal bands are surrounded by pictures of entirely different things, such as a flower, a teddy bear, a puppet, or the like. She explains that she really likes this unusual and surprising combination, and Louise adds that it is always so exciting when you see something that you have not seen or thought of before.

After some time, we continue on to another museum, which is hosting an exhibition called "The New Italian Design." This exhibition presents a wide range of designers in such areas as product design, food design, graphics and much more, and, again, the designers are highly enthusiastic. As in the stores, it is not merely things like handbags, jewellery and other accessories that attract the designers' attention. Rather, it is more often other kinds of design that they find truly fascinating. One creation, in particular, called Un Seconda Vita-A Second Life-inspires Rebecca. At first glance, the creation shows a broken bowl, but broken in a particular way so that each of the broken pieces becomes a small plate. Rebecca says that she really likes this idea of something getting a second life, and she ponders over whether it could be applied to clothing as well. She tells me that she will indeed think more about this. In much the same way, various other creations become sources of possible new ideas, because they are found to be quite exceptional.

After a few hours, we decide to turn our attention to Milan's famous shopping areas. Since our plan is flexible, we spend the next hours going from shop to shop, looking at all sorts of things, including furniture, antiques, interior design, books, art, expensive designer clothes and mainstream fashion. We visit all those stores which, for one reason or another, attract our attention; for instance because of a great amount of weird stuff in the window, an unusual interior design, or something else. In these stores, the designers eagerly explore and discuss a large number of things, both the minor details and the overall construction of what they 
examine. In this respect, looking and touching are not always enough, as certain items of clothing must even be put on in order to see how they really look and feel.

Let this brief description suffice to emphasize that the designers demonstrate a quite extraordinary attention to everything and everyone around them; people, things, buildings, sounds, smells etc. According to the Creative Director, this kind of attention is apparently an inherent part of his personality:

"As a person, I am very curious. I see how people are dressed, what they are doing, how they are, and what they want to communicate in the way that they are dressing. So, I am always looking left and right, and sometimes it is too much. I have to admit that it has happened more than once that people have come up to me and said: 'Do you have a problem?' But the reason has always been that I was just attracted by a pair of jeans, a pair of shoes or whatever."

This heightened attention is precisely what we see turned on to its utmost level of intensity in Milan. As the designers go from shop to shop, and street to street, they carefully observe and explore a range of people and things, activating all their senses in the process. Things are touched, materials smelled, people observed, and so forth. In a sense, they appear much like a kind of "urban hunter," tirelessly in pursuit of things, pictures, atmospheres and other constituents that could provide food for thought, as it were. As Tim Ingold stresses, people who hunt for subsistence generally have a very intimate knowledge of the landscape and its plant and animal inhabitants (2000:111).

Importantly, hunters are also often associated with an animistic way of being (see, for example, Ingold 2000:111-131; Viveiros de Castro 1998; Willerslev 2007). As one of the earliest notions in anthropology, animism is traditionally known to denote the human tendency to endow nonhuman entities with human characteristics (Descola 1996:87; Willerslev 2007:2). Ingold points out, however, that the distinctive feature of the animist ontology is not so much the recognition that life is in things but rather that things are in life, caught up in a never-ending process of coming into being (2007:31). As he elaborates:

This [animism as a condition of being] could be described as a condition of being alive to the world, characterised by a heightened sensitivity and responsiveness, in perception and action, to an environment that is always in flux, never the same from one moment to the next (Ingold 2006:10).

In this condition of being, in other words, the world is a nascent world, continuously about to disclose itself for what it is. And this condition, Ingold goes on, is not just characteristic of animists in such regions as Amazonia or Siberia, but can also be seen among painters, as described by 
Merleau-Ponty. The painter, according to Merleau-Ponty, does not observe a pre-formed and complete world with the purpose of representing it. Quite the contrary, he relates to it as though it were continuously being born; that is, "as though at every moment the painter opened his eyes to the world for the first time" (ibid. 12).

I cannot conceive of a more accurate way of describing the heightened sensitivity and responsiveness of the designers in Milan. Creations in museums, clothing in fashion stores, people in the streets and so on are sensuously explored in every possible way, as if nothing like it has ever previously existed. While I was surely inclined to see entities-fixed and complete, however odd or remarkable they appeared-the designers always saw potentials, constantly exploring what things might become rather than what they were. Crucially, this is not just a matter of being "attuned to an impressive degree to modern developments," as Blumer has it (1969:279), but of relating to the world in a very particular way. Like many other hunters (Ingold 2000:51), the designers are present at the continued birth of the world-that is, at the fact that things are alive-for which reason they are not turned in upon themselves, but open to the world around them (cf. Ingold 2007:31-32). Catherine explained this to me surprisingly clearly:

"I think that it is very important to always look at things in a new way and never take things as they are. You have to be really openminded, and I think that you always have to, you know, look at everything that is happening around you, take everything inside in a way."

Is Catherine not a true animist? A designer has to be open-minded, never taking things as they are, always approaching life as a process of ongoing generation. As such, we get a first hint of why the Creative Director's statement about the new being in second-hand places may not be so paradoxical after all; even used things, and perhaps used things in particular, are alive and undergoing continuous growth.

Now, two points should be clear. First, the designers' sensuous immersion in clusters of inspiration bears testimony to the profound significance of space in processes of seeking inspiration. Becoming inspired cannot just happen anywhere, but needs to be initiated in a particular somewhere. The designers clearly find it crucial to get away from their everyday surroundings and immerse themselves in settings marked off from the ordinary, meaning that clusters of inspiration occupy a liminal position which renders it possible to turn them into spaces of "undreamt-of opportunities" (see Hastrup 2004:92). However, and this is the second point, such spaces emerge not as a simple effect of their liminal positions, but take form through the designers' distinct mode of relating to them: that is, as continuous birth. The designers' sensuous immersion in-and, not least, heightened responsiveness to-the ongoing generation of the world transform the clusters into a kind of magic space, 
a site "through which one can reappraise well-known spaces and imagine other textures of life' (ibid. 111). It is in this sense that the clusters of inspiration come to serve as capacitating spaces, if one is open to it; that is to say, they capacitate the agents immersed in them and being open to the continued birth of the world to become truly inspired. What this entails more precisely is, however, yet to be clarified.

\section{Jumping things-and the experience of being attracted}

In Milan, it is clear that not everything is considered fascinating and inspiring. Some things are more attractive than others, almost irresistibly drawing the designers' attention to them. In one way or the other, these things are stimulating and extraordinary, somehow standing out from the mass of other things. As art historian James Elkins notes, it is almost as if certain things possess such an irresistible effect that they tie us to them by little wires (1996:19). He puts forward the rather provoking idea that, instead of saying that humans are doing the looking, we might just as well argue that objects are trying to catch our eyes, their gleams and glints being a sort of hook that snares us. Thus, to go on an inspiration trip and immerse oneself in museums, stores or similar contexts is to be "like fish who like to swim in waters full of hooks' (ibid. 20). Of course, the designers are the ones in pursuit of things but, to turn our customary assumption upside down, suggesting that things catch our eyes rather than, or just as much as, our eyes capturing things is, I believe, a thoughtprovoking yet apt invitation in the light of the above animistic condition of being.

In the ethnographic studies, some of the most intriguing instances of animate things concern stones. Nurit Bird-David describes, for instance, how a man from the Nayaka, a hunter-gatherer community of South India, relates that his sister-in-law was one day sitting under a tree when suddenly a stone jumped into her lap. The man then points at the stone because it was exactly this stone and not just any stone which had proved its ability to jump (1999:74; see also Ingold 2000:97). Indeed, to a Western ear, such an experience may sound strange, really strange, but it is perhaps more common than we tend to think. Is it merely a coincidence, for instance, that the Creative Director argued that he was attracted by a pair of jeans or shoes, thus ascribing the force of the attraction more to the jeans and shoes than to himself? Moreover, the Un Seconda Vita creation also appeared to approach Rebecca as much as she was approaching it, since she was not looking specifically for this creation, but was rather drawn to it amongst the bulk of other creations. As such, the things perceived to be inspiring were always described as either wild, crazy, attractive, eye-catching, and so on, always causing a stir and thus capturing their attention. Could it be, then, that the inspiring things were not simply in life, as described earlier, but even jumped onto the designers just as the stone had jumped onto the Nayaka woman? 
On the face of it, such an idea may perhaps appear outlandish, evidently challenging basic modernist conceptions and certainties which carefully separate subjects from objects, humans from things (see, for example, Latour 1993). As Ingold argues, it is customary for people in the West to conceive of life as a distinct qualifying attribute; that is, a property which only some entities and not others are believed to possess (2000:96). It follows, then, that insofar as the properly modern way of dealing with things is to perceive them as not possessing the property of life, belonging to the sphere of "lifeless" things separated from "lively" humans, they are naturally incapable of jumping. Clearly, the designers are not positioned outside but within such modernist conceptions, and, admittedly, none of them spoke explicitly about inspiring things "jumping onto" them.

However, this was what the Creative Director did say at one point: "I really go through the things," he said. "I let these things jump on me. I am absolutely open-minded. Whatever is coming, is coming." The famous British fashion designer, Alexander McQueen, similarly recalls how he once became inspired by a Peter Arnold orchid photograph when he stumbled upon the orchids in a one of his coffee-table books. Or, perhaps more to the point, the orchids stumbled upon McQueen. Because, as he explained, these orchids "were so striking and strange that they leaped out at me" (quoted in Armstrong 2007:361, emphasis added). While this indicates that the different structural positions between the designers on the floor and a Creative Director in charge significantly influence how they articulate what, the statement about jumping things is essentially a description of how inspiring things actively respond when one engages with them-a point which also the designers emphasize when they describe these things as wild, eye-catching, crazy, and so on, thus possessing a force of attraction. The question is, however, how are we to take such descriptions and experiences seriously, given our modernist inclinations? ${ }^{5}$

The Nayaka (Bird-David 1999), as well as the Ojibwa (Hallowell 2002[1960]) and the Yukaghirs (Willerslev 2007), may give us a clue. For them, life is not a property that entities may or may not possess a priori to their engagement in specific fields of relations. Rather, it is the other way around: things are perceived to be alive, some of them even to be persons, as and when and because people engage in and maintain relationships with them (Bird-David 1999:73). In other words, the quality of life is revealed not as an a priori property but after-the-fact; that is, life is a property of particular fields of relations and not of entities as such (Ingold 2000:96-98; Willerslev 2007:116-118). It is, therefore, mistaken to

\footnotetext{
${ }^{5}$ By taking it seriously, I mean not to dismiss the description as pure nonsense or explain it away by claiming that the Creative Director and the designers must clearly be talking in metaphors or articulating a romantic trope of artistic creation, as also stressed earlier.
} 
assume that these people perceive nonhuman entities, in general, as animate any more than we, as moderns, do (Hallowell 2002[1960]:24; Willerslev 2007:116-117). Rather, the important difference is that they see all entities, human and nonhuman, as potentially animate.

When inspiring things jump onto, or actively respond to, the Creative Director and the designers then, we ought not to take it to mean that they perceive of particular things as belonging to a category of the animate in a general sense. Rather, following their animistic tendencies, things are experienced to jump or respond, as, when and because they are involved in specific fields of relations and actual engagement. To put it differently, things are alive, jumping and responding, not as outward expressions of life as an innate property, but as the effects of being bound up together with the Creative Director and the designers in concrete contexts of practical engagement. Animism, as Rane Willerslev argues, is not "an explicitly articulated doctrinal system for perceiving the world," but rather "something that emerges in particular contexts of close practical involvement" (2007:8). This still leaves us, though, with two questions. Why are some things more attractive or inspiring than others? And what, in fact, does it entail that things are alive, jumping and responding when engaging with them?

\section{Engaging with things-and seeing from a new perspective}

If animate things emerge in and through their close practical engagement with the Creative Director and the designers, it follows that an answer to these questions must be sought in a thorough exploration of this engagement. In an interview with Lisa, one of the designers from the trip to Milan, this comes up rather suddenly as she looks at my recorder and says: "Another area of knowledge which I think is important is to be able to make a connection; for instance, if I see a recorder, to be able to imagine it or to translate it into a shirt." I have absolutely no clue as to what a shirt inspired by a recorder would look like. But it should be clear that the engagement between Lisa and the recorder cannot be entirely understood as an act of bricolage (Lévi-Strauss 1966), as so many other discussions of creativity and design have it (see, for example, Friedman 2001; Louridas 1999). Lisa does resemble a bricoleur in the sense that she engages "in a sort of dialogue with" the recorder in order "to discover what [it] could 'signify'” (Lévi-Strauss 1966:18). She may also be claimed to interrogate an already existing "set of tools and materials" (ibid. 17). But, like the Creative Director always visiting second-hand stores, the point is not that she reorganizes these elements and thus creates an unprecedented combination between a recorder and a shirt. This should be even clearer when we listen to Catherine, who does not zoom in on my recorder, but on a lamp:

"I could also take that lamp over there and say, 'Okay, this is my inspiration.' You can get something out of it. It is no problem. You 
can do a collection with this lamp as an inspiration. It just has to be your inspiration. I could see, for example, big white tops, and then really thin trousers. It is just an example, and that would run through. And then this round shape of it, you could try to have this as a topic going through as well. I would do big tops with thin trousers, and then I would find something else. I think that this round shape could be included as well."

This is hardly a bricoleur who speaks, not even if we recall the point that bricolage is not only a technical but also an intellectual activity (ibid.). The engagement between Catherine and the lamp is not one of reorganization, producing transformation or newness through an act of combining the lamp with tops and trousers. Rather more like the engineer who, as LéviStrauss emphasizes, "is always trying to make his way out of and go beyond the constraints imposed" (ibid. 19), Catherine seeks to envisage a fashion collection in a new way. At issue, then, are both elements of bricolage-that is, working with signs already established-and elements of engineering-that is, pointing towards concepts yet to come. So how are we to conceive of the engagement between Catherine and the lamp?

In his book on the nature of seeing, intriguingly entitled The Object Stares Back (1996), Elkins takes as his starting point the common assumption that seeing is "just looking;" that is, we open our eyes, light comes in, and we see the world. Seeing is, in this way, a passive, unthinking act, which builds on the idea that the observer and the object are two separate entities; the observer looks at the object as if from a detached position (ibid. 17-19). Elkins contends, however, that all of this is a lie. There is no fixed observer, no fixed object and no such thing as "just looking." In fact, the reduction of seeing to a formula with a looking subject and a seen object is far too simple (ibid. 35). Rather, the observer and the object are entangled in the sense that the former's gaze shoots out towards the latter from which light travels back to the former, altering the one and the other in the process (ibid. 43). This may sound a bit knotty, but Elkins emphasizes that seeing is essentially a reciprocal process. His argument goes something like this: when I look at someone, and this someone looks back at me, I watch how he or she responds to me so as to gain an updated sense of myself. As I see, I therefore also see myself being seen, which is to say that I see myself from the point of view of the person that I am seeing (ibid. 70-71). Now, Elkins's thought-provoking point is that this process includes objects as well. In brief, objects grow eyes and stare back:

Each object has a presence-a being and a face of its own-and if we take that seriously (not as a vague intuition but as a fact of vision), then the world is full of eyes. Seeing is being seen, and the world is so crowded with things that see and stare that we can stand to be aware of only a tiny fraction of them: more would overwhelm us (ibid. 12). 
Elkins argues, in other words, that seeing is not just something that we do but something that happens to us (ibid. 35). When we look at an object, it looks back, as it were, and we come to understand something, not merely about the object but also about ourselves. For instance, looking at a book may give us information about the book but, at the same time, it may also remind us of the particular point in time when we were interested in that book (ibid. 74). To see is, in a nutshell, also to be seen.

Although Elkins is solely concerned with the nature of seeing, his line of reasoning may provide us with an idea as to how we might construe the designers' broader sensuous engagement with things around them. Catherine tells us that she could easily take the lamp as her source of inspiration. In fact, it would cause her no problems, since she could see big white tops, thin trousers and something with a round shape. Like the sensuous engagement with things in Milan, she explores the lamp carefully-its colour, its materials, its construction, and so on-and, in this process, the lamp stares back, as it were, making a difference to how Catherine envisages a fashion collection. The question seems to be: what is it that the lamp says? In a paper intriguingly entitled "Can the Thing Speak?", Martin Holbraad suggests that things may be said to have their own language-"thingese," he calls it-which consists of their material characteristics. These, he emphasizes, "can dictate particular forms for their conceptualization" (2011:18), meaning that things may yield their own concepts and speak for themselves, if you will (ibid. 17-19). As Catherine explores the lamp, it stares or speaks back in a way that calls into question our common (modern) distinction between concepts and things (see Henare et al. 2007b). The design of the lamp and its material characteristics yield a concept of its own in the sense that the lamp provides a distinctive perspective on how a fashion collection may be envisaged. As a kind of effect of the lamp, Catherine sees big white tops, thin trousers, and something with a round shape.

In this way Catherine enters into a practical engagement with the lamp, whereby she explores it with all her senses, and whereby she comes to see herself being seen, to follow Elkins's reasoning. In a sense, she comes to see herself from the point of view of the lamp; or, to be more precise, she comes to see a possible new fashion collection from this distinct perspective. ${ }^{6}$ The lamp, Un Seconda Vita and other things are thus being both "looked at" and "looked from" in the same process, with the effect that they come to constitute distinct perspectives from which a fashion collection may be envisaged. As such, the engagement is not a one-way relatedness, as the designers are not approaching things as passive objects for their explorative gaze. Quite the reverse, things are perceived as being alive, caught up in a continuous birth, for which reason

\footnotetext{
${ }^{6}$ I thank Morten Axel Pedersen for being the one who first suggested that Catherine was looking from the point of view of the lamp. The way in which I have pursued this idea is, however, my responsibility alone.
} 
the engagement is a two-way responsive relatedness characteristic of an animistic condition of being. As Bird-David describes what she calls an "animistic epistemology," epitomized in the phrase that the Nayaka are "talking with" things:

"Talking with" stands for attentiveness to variances and invariances in behavior and response of things in states of relatedness and for getting to know such things as they change through the vicissitudes over time of the engagement with them. To "talk with a tree"-rather than "cut it down" [the modernist epistemology]-is to perceive what it does as one acts towards it, being aware concurrently of changes in oneself and the tree. It is expecting response and responding, growing into mutual responsiveness and, furthermore, possibly into mutual responsibility (1999:77, original emphasis).

This kind of animistic epistemology characterizes also the designers. Their close practical engagement with a lamp, a recorder, Un Seconda Vita, and so on is likewise one of "talking," in that the designers are highly attentive to the ways in which these things respond as they come closer to them, look carefully at them, touch them, smell them, and so forth. In this sense, things are, to quote Elkins, "no longer just things out there to be seen but also places where I can think about seeing and being seen" (1996:70). In brief, they constitute points of view which stare and talk back.

All of this is momentous. When the designers pursue new inspiration, they enter into mutually responsive engagements with a range of things. This entails that, in the process of exploring these things, they come to see themselves from the perspective of those things; or, to be more precise, the things come to represent distinctive points of view from which they can envisage potentially new fashion collections. The key point is, thus, that the things afford (cf. Gibson 1979) distinctive possibilities in the engagement with them; that is, they form part of a "circuit of affordances," as Moeran has aptly termed it (2014), in that they afford particular forms of conceptualization (Holbraad 2011:18).

Although the designers engage with all things in this manner due to their animistic tendencies, only certain things stare or talk back in ways that firmly capture their attention. These things possess this force of attraction because the forms for their conceptualization-that is, their distinctive points of view-allow the designers to impose a spatial distance on current things and phenomena, enabling them to see a fashion collection in an unprecedented way. This suggests, finally, why the Creative Director is so excited about second-hand stores; for in these stores, things and signs established in the past are carefully interrogated (bricolage), and precisely because they constitute uncommon perspectives, they enable him to "cut" his existing points of view and thus move beyond present-day canons (engineering). The inspiring things are, 
therefore, always jumping or responding, being wild, crazy and extraordinary, as the two-way responsive engagement with them grants access to new perspectives.

\section{Connecting with the zeitgeist-and entering a prophetic condition}

While the engagement between the things and the designers may perhaps appear somewhat fetishistic (see e.g. Ellen 1988; Hornborg 2006) as the former not only respond to but exert a significant effect on the latter, I shall now argue that the designers become possessed, not so much by particular things, as by a distinctive spirit: namely, the zeitgeist. There is, as such, a quite intricate relation between immersing oneself in concrete material surroundings and connecting with a spiritual realm. In what follows, I seek to clarify this relation.

To get at this issue, we shall begin with the intriguing observation that the designers clearly find numerous things to be inspiring as we tour Milan. So how can they determine, as sociologist Patrik Aspers asks, "among the things that they are inspired by, what actually to do" (2006:749)? Faced with this question, it is typical to hear designers object that "this is so difficult to talk about" (see also ibid. 750). In addition, they often refer to a certain bodily feeling, which might be described as a kind of "gut feeling" or "fingerspitzengefühl" (cf. Aspers 2001:45-46; Entwistle 2009:131). Listen, for instance, to Lisa:

"You have to have a certain feeling about trends. You have to have a sensibility to see which things exist right now, so that you can say that 'now, it is enough about those things; now, we need to have something new.' Yeah, a special sense maybe."

This special sense or feeling may call to mind Pierre Bourdieu's notion of practical sense or "feel for the game," which denotes the "capacity for practical anticipation of the "upcoming' future contained in the present" (1990:66). This capacity is produced by experiences of the game and its structures (ibid.), and one could presumably argue that good designers acquire such a capacity by being so engaged in the field of fashion that an anticipation of the future becomes possible. This is, in fact, what sociologist Joanne Entwistle argues in an analysis of fashion buyers at Selfridges department store. These buyers rely not only on codified forms of knowledge and rational calculation, but also on what Entwistle describes as tacit aesthetic knowledge: "an expressive and embodied knowledge derived out of a historical and collective disposition, or fashion habitus" (2009:139, original emphasis).

In the present context, however, I think that there is more to it than that. Recalling the statements at the beginning of this article, Catherine explained, for instance, that "you always have to be in the zeitgeist," since this enables you to "know basically what people are going to like in maybe one year." Rebecca said more or less the same thing, and 
they both argued that connecting with the zeitgeist is possible if one is highly attentive to the world, knowing much about what goes on in the present. Now, does this amount to what Bourdieu calls "a feel for the game" and what Entwistle terms "tacit aesthetic knowledge"? Although such concepts might prove illuminating in certain ways, the resulting analysis would essentially suffer from a crucial flaw: namely, that of too quickly substituting an unfamiliar expression-that is, the zeitgeist-for a familiar one-a feel for the game (Latour 2005:47-49). Hence, instead of explaining away the zeitgeist, I suggest that we hold our sense of wonder in suspension so as to seize on it as fertile analytical opportunity, thus adopting a strategy of "purposeful naïveté" (Henare et al. 2007a:2).

In this endeavour, we shall listen carefully to the Creative Director. In a presentation inside HUGO BOSS, he addressed the issue of how he decides what to do:

“It comes quite automatically for me. I don't have a crystal ball. I just have a feeling that tells me what is right, or what I think is right, and what is not right. [...]

"In a way, it's just to follow the wave, because, from my point of view, a designer is a kind of shaman. It is a person who has a possibility of catching something which is not really visible; something which is in the air, which everybody can breathe, but which only some people have the possibility, or the faculty, of translating into reality, into real and concrete things. [...]

"So, it is very esoteric, untouchable elements which we have to put inside and provide. And I know very well that this is difficult to understand but, believe me, it's also very difficult to explain, because we're talking about fresh air, or at least a feeling. It's not mathematics or physics. I strongly believe that there are energies in nature which are moving things, which are not visible, and which few people have the chance to catch. That is the reason why I make the comparison between the designer and the shaman, because the shaman is also a person who moves from the regular level to another level in order to catch what is there and bring it back."

Here, the Creative Director provides us with another, more detailed, account of the zeitgeist, although he does not use precisely this term. ${ }^{7}$ As untouchable and invisible yet in the air as something everybody can breathe, but only few people are able to capture and translate into tangible things, the zeitgeist is not embodied in particular material objects, as the notion of fetishism would suggest (Ellen 1988:218). Nor is it perceived as a person and manifested as a human, an animal or some

${ }^{7}$ He used the term in various other statements, however, arguing, for instance, that "we follow the wave, the spirit of the time, which is, in the end, the same thing." 
other concrete entity, as numerous anthropological studies of spirits have shown (Morris 2006:15). Rather, as a very distinct type of spirit, the zeitgeist is an omnipresent medium in which we are all essentially immersed as we continuously breathe it, not unlike the air, wind and weather which we likewise cannot touch but only touch in, as Ingold describes it (2007:29). We simply are in the zeitgeist. But if this is so, what is it that makes certain people like the designers able to connect with it, and others not?

With his analogy to shamans, the Creative Director gives us a clue worth pursuing. In the anthropology of religion, shamanism has been widely debated but is commonly known to denote a spirit-medium, with the ability to serve as a bridge between the spirit world and the human world (Morris 2006:17-18). As defined by Ioan Lewis, a shaman thus represents "an inspired prophet or leader, a charismatic religious figure with the power to control the spirits, usually by incarnating them' (quoted in ibid. 18). As spirits speak through a shaman, spirit possession is an intrinsic part of the shaman's capacity to master the spirits (ibid. 24). Importantly, Eduardo Viveiros de Castro elaborates that this capacity rests on a particular mode of knowing: animism (2004:468-469). It is only by, first, perceiving an animate world and, second, exploring it through a relational stance-that is, by entering into a reciprocal engagement in order "to take on the point of view of that which must be known" (ibid. 468)-that shamans come to be possessed by the spirits and, thus, to know and control them by adopting their perspectives. Shamanism presupposes, in other words, an animistic mode of knowing which essentially grows from the knower's reciprocal relatedness with the known (Bird-David 1999:78); that is, it entails "close and immediate relationships with the divinities or the spirits" (Morris 2006:23).

The designers' acute attentiveness to, and two-way engagement with, everything and everyone around them constitutes an animistic mode of knowing, which, I contend, forms the basis for a shamanic practice by which they connect with the zeitgeist. Since the zeitgeist is an omnipresent medium flowing through us all, humans and nonhumans, it follows that it can be known or mastered only by attending to and exploring everything carefully. In fact, Catherine stated rather clearly that connecting with the zeitgeist comes about by being highly attentive to the present, just like the Creative Director argued that he is "always looking left and right." In Milan, the designers likewise displayed a heightened sensitivity to, and entered into mutually responsive engagements with, a multitude of things. As "something which is in the air, which everybody can breathe," as the Creative Director explained, the zeitgeist is at once everywhere and nowhere but not, however, accessible to anyone. Rather, connecting with it hinges on the designers' animistic condition of being according to which things are not only alive and active but explored and known through a mutual responsive engagement with them; that is, through a particular mode of relating which not only the designers make 
happen but also happens to them. The zeitgeist, I argue, appears precisely in and through this reciprocal relatedness by which the designers, in their exploration of various things during inspiration trips, "open" themselves to the forces or perspectives of the world around them. Their animistic inclinations thus underlie a shamanic practice which makes them inspired.

The key point of this is not only that the designers gain a finetuned sense of what is happening, but of what is going to happen. "If you know a lot about what is happening in the world," as Catherine said, "you can also already imagine how things might be in one or two years' time." In this sense, the future is not detached from the present, but closely linked to it, so that the designers, when connecting with the zeitgeist, essentially become stretched out, as it were, between different points in time (cf. Nielsen 2011:398). Or, as Kirsten Hastrup describes the prophetic condition: "While situated in the 'old' world, prophets give voice to a 'new' one" (1989:224). The connection with the zeitgeist thus entails that the designers come to see, or see from, a future point in time. Hence, they can determine what to do and, as a distinct yet not detached temporal moment, the future informs decisions and actions here and now; that is, the present is reimagined from the perspective of the future (see also Miyazaki 2006; Nielsen 2011).

Importantly, however, this reimagination ought not to be from a too distant future. As often stressed by the designers, they must be ahead of the market but not too much ahead, because this will lead to fashion collections that consumers are not ready for. They should, therefore, not to be one pace ahead but only half a pace, as the advertising professionals in Moeran's ethnography have it (1996:138). As such, their challenge consists of freeing themselves from the present while remaining anchored in it (Hastrup 2004:194), imposing a temporal distance which allows them to see the present from the perspective of the future but also, in a sense, to see the future from the perspective of the present. To be possessed by the zeitgeist is, I contend, to occupy such a prophetic condition.

\section{Foretelling the future-and upholding a profound naïveté}

A popular saying, famously stated by Abraham Lincoln, has it that "the best way to predict the future is to create it." In a discussion of "the voice of prophecy," Edwin Ardener likewise emphasizes that prophecies are not about predicting the future, but about foretelling it; that is, a prophet not merely discovers a new reality, but conceptualizes and defines it (1989). This is precisely what is considered an imperative in modern capitalist business, permeated as it is by a "create/innovate or die" mantra (Jeanes 2006:127), impelling companies to continually stake out new paths into the future. In fact, the ability to foretell the future-and, as such, to conquer and colonize it-is apparently what distinguishes the winners 
from the losers. The business of fashion is perhaps the epitome of, or even model for, this conviction (see Löfgren 2005), given that its very raison d'être is to establish a discontinuity with what exists.

In this article, my argument has been that fashion designers approach this imperative by seeking inspiration, based on an animistic mode of being and involving a possession by a zeitgeist. While the inspiring things enable the designers to see a fashion collection from a new perspective, thus imposing a distance in a spatial sense, the possession by the zeitgeist makes them able to see, and see from, a point in the future, thus imposing a distance in a temporal sense. Catherine, for instance, may envisage a collection from the point of view of a lamp, but, in order to know if this viewpoint is worth pursuing, she needs to engage with, and open herself to, the multitude of perspectives around her in order to connect with the zeitgeist and see from the future. In this way, processes of inspiration amount to a distinctive technology of prefiguration-a mode of delving into and foretelling what is yet to come-by which the designers become able to act under a condition of inherent uncertainty. In a nutshell, they come to obtain prophetic points of view.

More generally, this attests to the ways in which humans tend to engage with certain nonhuman others, particularly spiritual beings, in contexts of high uncertainty. Rather than representing "an idle metaphysical tenet," animism denotes a distinctive mode of relating to nonhuman others, which "can be put to systematic and deliberate use" (Viveiros de Castro 2004:469). Importantly, the analysis presented here explicitly challenges any modernist assumption which strictly separates inert objects from active subjects, lifeless things from lively humans-and, by implication, associates animistic inclinations with pre-moderns only. Because "is it really true," Alf Hornborg asks, "that we, modern "Westerners", do not animate the objects around us?' (2006:22, original emphasis). The fashion designers, I believe, provide us with a clear answer, demonstrating how animism (together with shamanism) unfolds under certain circumstances of practical engagement (Hallowell 2002[1960]:24; Willerslev 2007:8). This, indeed, should caution us against undue exotization of those people portrayed as "animists." Even modern capitalist business thrives on animist and shamanic practices.

Underlying this argument is what I take to be an essential (business) anthropological ambition to learn how the involved agents themselves perceive their endeavours. If, to us, the designers' account of a zeitgeist, or the Creative Director's experience of jumping things appears somewhat odd, if not even nonsensical, the problem is ours and not theirs (see also Henare et al. 2007a:6). The point is, then, to probe ever more deeply into our astonishment and seize on it as an analytical opportunity to challenge our common understandings. Such a strategy of "purposeful naïveté" (ibid. 2) is not least significant in business anthropology where a 
core methodological task is, to quote Jakob Krause-Jensen, "to maintain a constant awareness of the differences that underlie the surface similarity in the often-identical [...] concepts used by the ethnographer and the informants" (2010:20). As a notion, the zeitgeist was of course familiar to me but, as a being in the world, it was entirely unfamiliar, let alone the animistic mode of relating by which to become possessed by it. Business anthropology, I think, will do well to uphold a profound sense of naïveté which will open up, rather than close down, our conception of the world of modern business-of what it is composed and what it is like to be in it. This is, perhaps, the very purpose of a business anthropology.

\section{References}

Ardener, Edwin. 1989. The Voice of Prophecy. Further Problems in the Analysis of Events. In The Voice of Prophecy and Other Essays (pp. 134154). Oxford: Basil Blackwell.

Armstrong, Lisa. 2007. The Diary of a Dress: Alexander McQueen Shares the Saga of How One of His Inspirations-A Peter Arnold Orchid Photograph-Evolved from Simple Sketch to Production Nightmare to a Stunning Gown Fit for Supermodel Naomi Campbell. In The Fashion

Reader, edited by L. Welters and A. Lillethun (pp. 361-363). Oxford \& New York: Berg.

Aspers, Patrik. 2001. Markets in Fashion. A Phenomelogical Approach. Stockholm: City University Press. 2006. Contextual Knowledge. Current Sociology 54 (5):745-763.

Bird-David, Nurit. 1999. "Animism" Revisited: Personhood, Environment, and Relational Epistemology [and Comments and Reply]. Current Anthropology 40 (Supplement):67-91.

Blumer, Herbert. 1969. Fashion: From Class Differentiation to Collective Selection. The Sociological Quarterly 10 (3):275-291.

Bourdieu, Pierre. 1990. The Logic of Practice. Cambridge: Polity Press.

Caves, Richard. 2000. Creative Industries. Contracts Between Art and Commerce. Cambridge, MA: Harvard University Press.

Davis, Fred. 1992. Fashion, Culture, and Identity. Chicago \& London: The University of Chicago Press.

Descola, Philippe. 1996. Constructing natures. Symbolic ecology and social practice. In Nature and Society. Anthropological Perspectives, edited by P. Descola and G. Pálsson (pp. 82-102). London: Routledge.

Eckert, Claudia, and Martin Stacey. 1998. Fortune Favours Only the Prepared Mind: Why Sources of Inspiration are Essential for Continuing Creativity. Creativity and Innovation Management 7 (1):9-16. 
Elkins, James. 1996. The Object Stares Back. On the Nature of Seeing. San Diego, New York \& London: Harcourt, Inc.

Ellen, Roy. 1988. Fetishism. Man (N.S) 23:213-235.

Entwistle, Joanne. 2000. The Fashioned Body. Fashion, Dress and Modern Social Theory. Cambridge \& Malden, MA: Polity Press. 2009. The Aesthetic Economy of Fashion. Markets and Values in Clothing and Modelling. Oxford \& New York: Berg.

Friedman, Jonathan. 2001. The Iron Cage of Creativity: An Exploration. In Locating Cultural Creativity, edited by J. Liep (pp. 46-61). London: Pluto Press.

Gibson, James J. 1979. The Ecological Approach to Visual Perception. Boston: Houghton Mifflin.

Hallowell, A. Irving. 2002[1960]. Ojibwa ontology, behavior, and world view. In Readings in Indigenous Religions, edited by G. Harvey (pp. 17-49). London \& New York: Continuum.

Hamel, Gary, and C. K. Prahalad. 1996. Competing for the Future. Boston, MA: Harvard Business School Press.

Hastrup, Kirsten. 1989. The Prophetic Condition. In Edwin Ardener. The Voice of Prophecy and Other Essays (pp. 224-228). Oxford: Basil Blackwell. 2004. Action. Anthropology in the Company of Shakespeare. Copenhagen: Museum Tusculanum Press.

Henare, Amiria, Martin Holbraad, and Sari Wastell. 2007a. Introduction: Thinking through things. In Thinking Through Things. Theorising Artefacts Ethnographically, edited by A. Henare, M. Holbraad and S. Wastell (pp. 131). London \& New York: Routledge. , eds. 2007b. Thinking Through Things. Theorising Artefacts Ethnographically. London \& New York: Routledge.

Holbraad, Martin. 2011. Can the Thing Speak? In Working Papers Series \#7: Open Anthropology Cooperative Press.

Hornborg, Alf. 2006. Animism, Fetishism, and Objectivism as Strategies for Knowing (or not Knowing) the World. Ethnos 71 (1):21-32.

Ingold, Tim. 2000. The Perception of the Environment. Essays in livelihood, dwelling and skill. London \& New York: Routledge.

-------. 2006. Rethinking the Animate, Re-Animating Thought. Ethnos 71 (1):9-20.

2007. Earth, Sky, Wind, and Weather. Journal of the Royal Anthropological Institute 13 (S1):S19-S38.

--------. 2008. Anthropology is Not Ethnography. Proceedings of the British Academy 154:69-92. 
Jackson, Michael. 2013. Lifeworlds. Essays in Existential Anthropology. Chicago \& London: The University of Chicago Press.

Jeanes, Emma L. 2006. "Resisting Creativity, Creating the New." A Deleuzian Perspective on Creativity. Creativity and Innovation Management 15 (2):127-134.

Jiménez, Alberto Corsín. 2003. On Space as a Capacity. Journal of the Royal Anthropological Institute 9 (1):137-153.

2013. Introduction. The Prototype: More than Many and Less than One. Journal of Cultural Economy.

Krause-Jensen, Jakob. 2010. Flexible Firm. The Design of Culture at Bang \& Olufsen. New York \& Oxford: Berghahn Books.

2013. Counter-espionage. Fieldwork among Culture Experts in Bang \& Olufsen. In Organisational Anthropology. Doing Ethnography in and among Complex Organisations, edited by C. Garsten and A. Nyqvist (pp. 43-57). London: Pluto Press.

Latour, Bruno. 1993. We Have Never Been Modern. London: Prentice Hall. 2005. Reassembling the Social. An Introduction to Actor-NetworkTheory. Oxford: Oxford University Press.

Lévi-Strauss, Claude. 1966. The Savage Mind. London: Weidenfeld and Nicolson.

Louridas, Panagiotis. 1999. Design as Bricolage: Anthropology Meets Design Thinking. Design Studies 20:517-535.

Löfgren, Orvar. 2005. Catwalking and Coolhunting. The Production of Newness. In Magic, Culture and the New Economy, edited by O. Löfgren and R. Willim (pp. 57-71). Oxford \& New York: Berg.

Mete, Fatma. 2006. The Creative Role of Sources of Inspiration in Clothing Design. International Journal of Clothing Science and Technology 18 (4):278-293.

Miyazaki, Hirokazu. 2006. Economy of Dreams: Hope in Global Capitalism and Its Critiques. Cultural Anthropology 21 (2):147-172.

Moeran, Brian. 1996. A Japanese Advertising Agency. An Anthropology of Media and Markets. London: Curzon.

--------. 2005. The Business of Ethnography. Strategic Exchanges, People and Organizations. Oxford \& New York: Berg.

2014. The Business of Creativity. Toward An Anthropology of Worth. Walnut Creek, CA: Left Coast Press.

Morris, Brian. 2006. Religion and Anthropology. A Critical Introduction. Cambridge: Cambridge University Press. 
Negus, Keith, and Michael Pickering. 2004. Creativity, Communication, and Cultural Value. London, Thousand Oaks, California \& New Delhi: SAGE Publications.

Nielsen, Morten. 2011. Futures within: Reversible Tme and Housebuilding in Maputo, Mozambique. Anthropological Theory 11 (4):397-423.

Salamon, Karen Lisa G. 2005. Possessed by Enterprise. Values and Valuecreation in Mandrake Management. In Magic, Culture and the New Economy, edited by 0. Löfgren and R. Willim (pp. 47-55). Oxford: Berg.

Vangkilde, Kasper Tang. 2013. In Search of a Creative Concept in HUGO BOSS. In Exploring Creativity. Evaluative Practices in Innovation, Design, and the Arts, edited by B. Moeran and B. T. Christensen (pp. 69-95). Cambridge: Cambridge University Press.

Viveiros de Castro, Eduardo. 1998. Cosmological Deixis and Amerindian Perspectivism. Journal of the Royal Anthropological Institute 4 (3):469488.

2004. Exchanging Perspectives. The Transformation of Objects into Subjects in Amerindian Ontologies. Common Knowledge 10 (3):463484.

Willerslev, Rane. 2007. Soul Hunters. Hunting, Animism, and Personhood among the Siberian Yukaghirs. Berkeley, Los Angeles \& London: University of California Press.

Kasper Tang Vangkilde is Associate Professor at Department of Anthropology, School of Culture and Society, Aarhus University. His main research interests are within the fields of business, organizational and design anthropology, with particular emphasis on processes of creativity, branding, management and organization. He holds a Ph.D. in Anthropology (2012) from the University of Copenhagen and is at present mainly responsible for the specialization in "Innovation, Organization and Work" on the Master's Degree Programme in Anthropology at Aarhus University. As member of the steering committee of the Research Network for Design Anthropology, he is co-editor of the forthcoming Design Anthropological Futures (Bloomsbury Academic, 2016). He can be reached at etnkvangkilde@cas.au.dk 